Down regulation of receptors depends on maintaining a continuously raised agonist concentration. While daily administration of high concentrations of the superactive agonist luteinising hormone releasing hormone analogue is capable of maintaining activity for prolonged periods, the fluctuation of blood concentrations may be the reason why rises in testosterone are sometimes seen during long term administration. Indeed, it is recognised with other peptide systems that maintaining a constant plasma concentration is critical in producing down regulation (unpublished observation). Thus there is every reason to suppose that a constant availability such as is produced by depot administration is likely to be more effective in maintaining the down regulation.

The regulatory peptide control system in the body has been relatively recently discovered but it is clear that it is highly complex and has an important role in the control of every organ system. Pharmaceutical intervention in the regulatory peptide system therefore offers considerable therapeutic potential. This has already been exploited with such agents as captopril, preventing the production of an active peptide, and naloxone, blocking the natural peptide receptor. It has not been possible, hitherto, to contemplate long term administration of peptide as treatment except in extreme circumstances, such as diabetes mellitus, where a poor drug delivery system is tolerable only in the face of a dire alternative. The availability of a safe, effective long term depot, which is capable of fulfilling this role, may therefore have a wide application, particularly as other superagonist regulatory peptides are developed.

1 Post EM, Richman RA, Blackett PR, Duncan KP, Miller K. Desmopressin

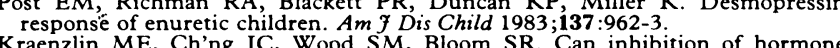
section secretion be associated with endocrine tumour shrinkage ? Lancet 1983;ii:1501. cancer: treatment with a long acting LHRH analogue. Br $\mathcal{F}$ Urol 1983;55 743-6.

4 Kerle D, Williams G, Ware H, Bloom SR. Failure of long term luteinising hormone releasing hormone treatment for prostatic cancer to suppress serum luteinising hormone and testosterone. Br Med F 1984;289:468-9.

5 Sellman ELY, Sanderson JE, Wentworth R. Lactic glycolic acid polymers. In Gregoriadis G, ed. Drug carriers in biology and medicine. New York: Academy

Press, 1979:264-70

(Accepted 24 September 1984)

Hammersmith Hospital and Royal Postgraduate Medical School, London

GORDON WILLIAMS, FRCS, consultant urologist

DAVID KERLE, FRCS, senior registrar in urology

STEPHEN GRIFFIN, MB, BS, senior house officer in urology

HELEN DUNLOP, BSC, research assistant in urology

STEPHEN R BLOOM, FRCP, professor of endocrinology

Correspondence and requests for reprints to: $\mathrm{Mr} \mathrm{G}$ Williams, Department of Urology, Hammersmith Hospital, London $W 12$ oHS.

\section{Urinoma complicating papillary necrosis in diabetes}

The term urinoma describes an encapsulated collection of urine that has extravasated from the upper renal tract. We describe a case in which a urinoma formed secondary to ureteric obstruction caused by a sloughed papilla.

\section{Case report}

A 76 year old woman with maturity onset diabetes normally controlled by diet presented with left sided abdominal pain, polydipsia, polyuria, and confusion of one week's duration. She was severely dehydrated with tenderness in the left flank. On admission her blood glucose concentration was $39 \mathrm{mmol} / \mathrm{l}(703 \mathrm{mg} / 100 \mathrm{ml})$ with no evidence of metabolic acidosis or hypernatraemia. The white cell count was $20.8 \times 10^{9} / 1$ with $83 \%$ neutrophils. Blood and urine cultures were sterile despite the lack of previous antibiotic treatment. She rapidly improved after administration of insulin and intravenous fluids, but the abdominal pain persisted.

Abdominal ultrasound (figure) showed the presence of a transonic mass adjacent to the lower pole of the left kidney, and high dose (100 ml Conray 325) intravenous urography confirmed the presence of an extrinsic mass causing lateral displacement of the kidney. The left collecting system was slightly distended and contained several lucent filling defects, particularly in the upper group of calices. The right kidney was normal. The findings on intravenous urography were consistent with unilateral papillary necrosis.

The transonic mass was aspirated percutaneously under ultrasound control, producing $150 \mathrm{ml}$ straw coloured sterile fluid with 3850 white cells/l and a urea concentration of $17.6 \mathrm{mmol} / 1(106 \mathrm{mg} / 100 \mathrm{ml})$. On the

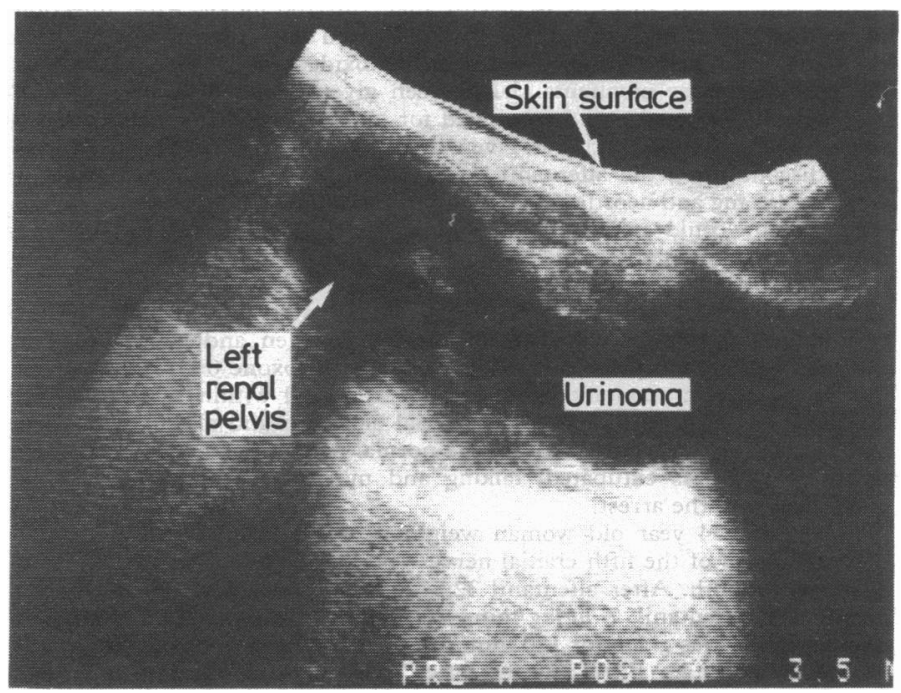

Prone sagittal ultrasound scan to left of midline.

same day the plasma urea concentration was $4.9 \mathrm{mmol} / 1(29 \mathrm{mg} / 100 \mathrm{ml})$, confirming that this fluid was indeed urine. One week later a second ultrasound examination showed that the mass had resolved, and amorphous debris was noted in the bladder. Microscopy of this showed white cells and epithelial cells but no recognisable papillary material.

\section{Comment}

Most urinomas described elsewhere resulted from accidental or surgical trauma, ${ }^{1}$ but spontaneous cases have been described secondary to ureteric obstruction with calculi, ${ }^{2}$ bladder and ureteric tumours, ${ }^{3}$ and bladder outlet obstruction. ${ }^{4}$

In this case there was evidence of papillary necrosis, urinary obstruction, and urinoma. We believe that the urinoma was secondary to transient ureteric obstruction by a sloughed papilla. One other case of urinoma in a diabetic with papillary necrosis has been reported, but a ureteric calculus was also identified. ${ }^{5}$ We therefore conclude that urinoma may be a rare complication of papillary necrosis.

1 Borkowski A, Gomula A, Waleck S. Encapsulated urinary extravasation (urinoma) as a late complication of ureterolithotomy and pyelolithotomy. Eur Urol 1981;

2 Kettlewell $M$, Walker $M$, Dudley $N$, et al. Spontaneous extravasation of urine secondary to ureteric obstruction. $\mathrm{Br} \mathcal{Z}$ Urol $1973 ; 45: 8-14$

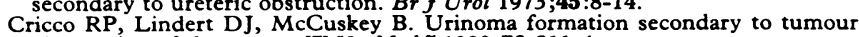

bstruction of the ureter. W Va Med 7 1980;76:311-4.

Singh B, Kim H, Wax SH. Peripelvic urinoma associated with benign prostatic

hypertrophy. Urology $1979 ; 14: 600-2$.

5 Khan AU, Malek RS. Spontaneous urinary extravasation. $\mathcal{f}$ Urol 1976;116:161-5.

(Accepted 24 September 1984)

St Peter's Hospital, Chertsey, Surrey KT16 OP2

M S DENNIS, MB, MRCP, medical registrar

$M$ HAYES, registrar in radiography

Correspondence to: Dr M S Dennis, St Thomas's Hospital, London SE1.

\section{Respiratory depression after alfentanil infusion}

Alfentanil (Rapifen) is a synthetic, short acting opioid, roughly one quarter as potent as fentanyl with one third the duration of action. Its pharmacokinetics render it suitable for administration by continuous intravenous infusion. ${ }^{1}$ We have been assessing the use of alfentanil by continuous infusion and report two cases of unexpected respiratory depression after its use.

\section{Case reports}

Case 1-A 72 year old man weighing $81 \mathrm{~kg}$ was scheduled to undergo cervical decompression. Premedication was with temazepam $30 \mathrm{mg}$ by 
mouth and he was anaesthetised with alfentanil $100 \mu \mathrm{g} / \mathrm{kg}$. After injection of vecuronium $6 \mathrm{mg}$ the trachea was intubated and intermittent positive pressure ventilation continued with nitrous oxide and oxygen. As soon as the induction dose of alfentanil had been given an infusion of alfentanil $1 \mu \mathrm{g} / \mathrm{kg} / \mathrm{min}$ was begun and continued for two hours. During this period a further $6 \mathrm{mg}$ vecuronium was given in divided doses. Fifty five minutes after discontinuing the alfentanil infusion and after the administration of atropine $1.2 \mathrm{mg}$ and neostigmine $2.5 \mathrm{mg}$ the endotracheal tube was removed. The patient could move all four limbs, was completely coherent and orientated, and remarked spontaneously: "I feel fantastic." Head lift was maintained for 20 seconds. Seventy minutes after stopping the infusion a sudden respiratory arrest occurred. No femoral pulse was palpable. After endotracheal intubation, ventilation with $100 \%$ oxygen, and external cardiac massage the femoral pulse was again palpable. Naloxone $0.4 \mathrm{mg}$ was given intravenously and spontaneous respiration returned within three minutes. Twelve lead electrocardiogram and arterial blood gas and plasma potassium and calcium values were all within the normal range. The patient gradually woke up and was extubated, talking and moving all four limbs within 180 minutes of the arrest.

Case 2-A 54 year old woman weighing $64 \mathrm{~kg}$ scheduled for vascular decompression of the fifth cranial nerve was premedicated with temazepam $30 \mathrm{mg}$ by mouth. After alfentanil $32.5 \mu \mathrm{g} / \mathrm{kg}$ and thiopentone $200 \mathrm{mg}$ an infusion of alfentanil $7 \mu \mathrm{g} / \mathrm{kg} / \mathrm{min}$ was given for 10 minutes and then $1.6 \mu \mathrm{g} / \mathrm{kg} / \mathrm{min}$ was given for 110 minutes. Curare $45 \mathrm{mg}$ was used for neuromuscular blockade. Fifty minutes after stopping the infusion and after atropine $1.2 \mathrm{mg}$ and neostigmine $2.5 \mathrm{mg}$ she woke up and was conversing normally, saying that her facial pain was completely cured. Thirteen minutes later she stopped breathing and was immediately reintubated. Spontaneous ventilation returned after naloxone $0.4 \mathrm{mg}$ was given intravenously. The radial pulse remained palpable throughout. Plasma alfentanil concentration at the time of the respiratory arrest was $95 \mu \mathrm{g} / \mathrm{l}$.

\section{Comment}

Respiratory depression is a well recognised complication after administration of opioid analgesics. The interesting feature of these two cases is that both patients had initial rapid, clear recovery from anaesthesia, with sudden respiratory arrest. Furthermore, the plasma alfentanil concentration in the second case was below that which would be expected to cause respiratory arrest. Unfortunately, the plasma alfentanil concentration was not measured in the first patient.

These respiratory arrests are unlikely to be due to second peaks in plasma alfentanil concentration as have been described for fentanyl, ${ }^{2}$ since all the available pharmacokinetic data suggest that plasma alfentanil concentrations decline exponentially after stopping administration. ${ }^{134}$ Possibly a decrease in ambient stimulation after transfer to the recovery ward may have been a contributory factor. Possibly also age was relevant in the first patient, as alfentanil elimination is prolonged with increasing age. ${ }^{4}$ Other workers have used infusion regimens with higher doses than we in 15 patients without problems with postoperative respiratory depression. ${ }^{3}$ Our two cases, however, occurred in a series of 26 patients who had received alfentanil. We therefore recommend that when alfentanil infusions are used, as with other opioids, respiration should be monitored very closely in the initial postoperative period.

Neither the Committee on the Safety of Medicines nor the manufacturers, Janssen Pharmaceutical Ltd, were aware of this potential problem with alfentanil. Nevertheless, since submitting this report we have learnt of a further, similar episode described in a patient in Canada. ${ }^{5}$

We thank Professor E S Watkins and Mr F Afshar for allowing us to study patients under their care and Janssen Pharmaceutical Ltd for supplies of alfentanil.

1 Bovill JG, Sebel PS, Blackburn CL, Heykants J. The pharmacokinetics of alfentanil (R39209): a new opioid analgesic. Anesthesiology 1982;57:439-43.

2 Stoeckel H, Hengstmann JH, Schuttler J. Pharmacokinetics of fentanyl as a possible explanation for recurrence of respiratory depression. $\mathrm{Br} \mathcal{J}$ Anaesth $1979 ; 51: 741-5$.

3 Ausems ME, Hugg CC. Plasma concentrations of alfentanil required to supplement nitrous oxide anaesthesia for lower abdominal surgery. $\mathrm{Br}$ f Anaesth $1983 ; 55: 191-75$

4 Helmers JHJH, Noorduin $\mathrm{H}$, Adam AA, Giezen J, van Leeuwen L. Anaesthesia with alfentanil in the geriatric patient. Anaesthetist $1983 ; 32: 228$

Can Angesth Soc $\mathcal{F}$, Grenier Y. Continuous infusion of alfe

Accepted 17 September 1984)

London Hospital Medical College, Whitechapel, London E1 1BB

P S SEBEL, PHD, FFARCSI, senior lecturer and consultant anaesthetist J M LALOR, MB, FFARCS, lecturer in anaesthesia

P J FLYNN, MB, FFARCSI, senior lecturer and consultant anaesthetist B A SIMPSON, MD, FRCS, senior registrar

Correspondence to: Dr P S Sebel, Anaesthetics Unit, London Hospital, Whitechapel, London E1 1BB.

\section{Management of retained biliary calculi: relaxation of sphincter induced by ceruletide}

Several non-operative techniques have been reported as effective in the management of retained stones after exploration of the common bile duct. Infusion of saline is of doubtful efficacy and infusion of cholate unreliable. ${ }^{1}$ Infusion of glyceryl mono-octanoate via a $T$ tube is effective but induces erosive duodenitis. ${ }^{2}$ Other methods of proved efficacy include endoscopic sphincterotomy and extraction of stones, and percutaneous removal via the $T$ tube tract. ${ }^{3}$ The first of these requires special skill, which is not available in many hospitals. Extraction via the $T$ tube tract with a catheter that may be guided and a flexible choledochoscope is effective but requires six weeks delay to allow for maturation of the $T$ tube tract. ${ }^{4} \mathrm{I}$ describe a simple method of treatment in which maximal relaxation of the sphincter was induced pharmacologically by ceruletide, which allowed large volumes of saline to be infused via the $T$ tube without a deleterious rise in biliary pressure. Ceruletide is the synthetic analogue of caerulein and elicits a powerful cholecystokinetic response with relaxation of the sphincter of Oddi. ${ }^{5}$

\section{Patients, methods, and results}

Four patients with retained ductal calculi were treated according to a preset protocol. All had undergone cholecystectomy during the same admission, with exploration of the common bile duct and insertion of an F16 $\mathrm{T}$ tube. The residual stones were diagnosed from a $\mathrm{T}$ tube cholangiogram obtained usually on the seventh postoperative day. Two patients had a single distal ductal calculus (radiological sizes 0.4 and $0.7 \mathrm{~cm}$ ), one had two small ductal calculi $(0.2 \mathrm{~cm})$, and the fourth had eight calculi of varying size (range $0 \cdot 2-0.8 \mathrm{~cm}$ ) in the common bile duct and a long cystic duct remnant. None of the patients had jaundice or any evidence of sepsis.

Ceruletide (Farmitalia) was administered intravenously in a dose of $2 \mathrm{ng} / \mathrm{kg} / \mathrm{min}$ in saline for one hour with a constant infusion pump. Five minutes after the start of the infusion sterile isotonic saline was infused via a disposable manometry line through the external limb of the $T$ tube at a rate that kept the biliary pressure at $25-30 \mathrm{~cm}$ water. The infusions were stopped after one hour and the $T$ tube connected to a bile drainage bag. The amount of saline infused averaged $2 \cdot 1$ (range $1-3$ ) litres. Prophylactic antibiotic treatment was administered as a single intravenous injection of $1 \mathrm{~g}$ cefuroxime half an hour to one hour before the procedure. $T$ tube cholangiography was performed before and after the procedure.

In three patients the biliary tree was clear of stones after one treatment. In the patient with multiple calculi six were flushed out by the first treatment but two remained in the cystic duct remnant. These were eliminated when the treatment was repeated a few days later. No cardiovascular side effects were noted during the procedure, but watery diarrhoea occurred in two patients who received more than 2.5 litres of saline via the $T$ tube during the treatment. A mild increase in serum amylase activity was observed in all four patients.

\section{Comment}

Administration of ceruletide as a constant infusion allows fairly large volumes of saline to be administered via the $T$ tube without an increase in biliary pressure beyond the physiological maximal hepatic secretory pressure of $28-30 \mathrm{~cm}$ water. This permits a short phase of enhanced flushing of the biliary tree, which together with the relaxation of the sphincter induced by ceruletide favours passage of residual calculi smaller than one $\mathrm{cm}$ into the gastrointestinal tract. The technique appears to be efficacious and free of serious side effects, and it should be used before more invasive methods currently available for dealing with this problem.

I thank Farmitalia Carlo Erba for supplying ceruletide.

1 Pitt HA, Cameron JL. Sodium cholate dissolution of retained biliary stones. Mortality rate following intrahepatic infusion. Surgery $1975 ; 85: 457-60$ 2 Mack EA, Patzer EM, Crummy AB, Hofman AF, Babayan VK. Retained biliary tract stones. Arch Surg 1981;116:341-4.

3 Safrany L. Endoscopic treatment of biliary tract diseases. An international study.

4 Berci G, Hamlin JA. A combined fluoroscopic and endoscopic approach for retrieval of retained stones through the T-tube tract. Surg Gynecol Obster $1981 ; 153: 237-40$

Ganzina F, Santamaria A. Caerulein (ceruletide). A revicw. Acta Gastroenterol
Belg 1976;39:169-85.

Accepted 2 October 1984)

University Department of Surgery, Ninewells Hospital and Medical School, Dundee DD1 9SY

A CUSCHIERI, MD, CHM, professor 